\title{
Postmyocardial Infarct Remodeling and Heart Failure: Potential Contributions from Pro- and Antiaging Factors
}

\author{
Halliday A. Idikio \\ Department of Laboratory Medicine and Pathology, University of Alberta, Room 5B4.11 WCM-HSC, 8440-112th Street, \\ Edmonton, AB, Canada T6R 2B7 \\ Correspondence should be addressed to Halliday A. Idikio, hidikio@ualberta.ca
}

Received 20 November 2010; Revised 14 February 2011; Accepted 14 February 2011

Academic Editor: Gerasimos Filippatos

Copyright (๑) 2011 Halliday A. Idikio. This is an open access article distributed under the Creative Commons Attribution License, which permits unrestricted use, distribution, and reproduction in any medium, provided the original work is properly cited.

\begin{abstract}
Myocardial infarction and adverse postinfarct remodeling in older persons lead to poor outcome and need greater understanding of the contributions of age-related factors on abnormal cardiac function and management. In this perspective, how normal aging processes could contribute to the events of post-myocardial infarction and remodeling is reviewed. Post-myocardial infarction and remodeling involve cardiomechanical factors and neurohormonal response. Many factors prevent or accelerate aging including immunosenescence, recruitment and regeneration of stem cells, telomere shortening, oxidative damage, antiaging hormones klotho and melatonin, nutrition, and Sirtiun protein family, and these factors could affect post-MI remodeling and heart failure. Interest in stem cell repair of myocardial infarcts to mitigate post-MI remodeling needs more information on aging of stem cells, and potential effects on stem cell use in infarct repair. Integrating genomics and proteomics methods may help find clinically novel therapy in the management of post-MI remodeling and heart failure in aged individuals.
\end{abstract}

\section{Introduction}

Aging is universal and is governed by may factors, the basis of which many be theoretical. The fundamental argument is whether aging is programmed or simply determined by interactions between environmental and genetic factors [1] (Table 1). Many are searching for human longevity genes but the efforts are complicated or compounded by the role of interdependent environmental factors. The factors suggested include insulin/insulin-like growth factor-1 (IGF-1), and Fox-head transcription factors (FOXOs) [2]. Klotho gene is a recent description of antiaging gene $[3,4]$. On the other side the Wnt canonical and alternate signaling pathways are participants in aging mainly in their regulation of stem cell renewal [5]. Moreover, the elderly experience worse heart failure postMI and are major demographic contributors to increase in heart failure burden [6]. The offsprings of centenarians have an advantage as they fare better with age, have less risk of cardiovascular disease and stroke [7]. Centenarian offsprings have longer telomeres and their experience suggests close interaction of environment and cellular repair systems[8]. Model systems have provided a wealth of information on the roles of altered genetic factors on aging [9]. Gene expression changes with aging in mice is available [10] and changes in gene expression in all organs with age are noted including 23 genes and 10 gene sets changed with aging mouse heart.

The present paper aims to summarize relevant ideas of normal aging process and factors involved in promoting or protecting tissue and organ aging. The changes in cardiac function and morphology with aging before onset of myocardial infarction (MI), myocardial infarction and remodeling and effects of aging factors and the search for ways to ameliorate the adverse outcome of postMI remodeling in older individuals including use of "stem cells" for infarct repair.

\section{Pro- and Antiaging Contributors}

Multiple factors, genetic and environmental, affect the aging/longevity process in cells, tissues and organ systems of humans. The theoretical factors of aging include somatic mutation, telomere loss, mitochondrial oxidative damage, and altered proteins, network theories; these factors do not 
adequately explain differences in longevity in model, wild animals and humans and as some organisms show no aging and as such studies in model organisms may not reproduce human aging adequately [1].

2.1. ROS-Induced Mitochondrial and DNA Damage. Reactive oxygen species (ROS) are generated from the mitochondria under normal conditions and increases with cellular stress. NADPH oxidase family of proteins (Nox1, Nox2, Nox3, Nox4, Nox5, Duox) are the most important for generating ROS in the heart and other tissues and cells $[11,12]$. Nox family oxidases contribute to cardiac hypertrophy and fibrosis [12]. ROS can damage DNA, proteins and can lead to cell death (apoptosis). ROS-induced DNA damage generate mutations as seen in mice and humans. There are intrinsic antioxidants such as the superoxide dismutases (copper/zinc and manganese). In animal models, the roles of molecules/genes in ageing are defined by using knockouts and mutations of individual molecules and the models generally lead to premature aging. Inadequate or poor DNAdamage and repair response leads to tissue stem cell depletion, senescence and apoptosis and ultimately aging [13]. Antioxidative enzymes such as superoxide dismutase (SOD) and catalase are also antiaging in model systems, though their contribution longevity in humans is debated [2].

2.2. Protein Misfolding and Aging. Heat shock proteins and their signaling pathways involved in cellular stress responses, responding protein misfolding, also promote aging when their functions decline [14].

2.3. Antiaging Hormone. A recently described antiaging gene in mouse knockout model, Klotho has many functions that include inhibition of insulin/insulin-like growth factor (IGF) signaling and oxidative stress $[4,15]$. Klotho interacts with and dampens Wnt signaling and loss of klotho l leads to more Wnt signaling [16]. Klotho can be measured in serum and cerebrospinal fliud. Klotho expression variations exist within populations with cardiac implications [17].

2.4. Diabetes and Aging. Mouse models of diabetes leads to aging of "cardiac stem cells" due to generation of ROS, DNA damage and cell death [18].

2.5. Micronutrient Inadequacy. The Sirtiun family of proteins [19] (nuclear Sirt 1, 6, and 7, cytoplasmic Sirt 2, and mitochondrial Sirt 3-5) are involved in the response of cells to environmental and dietary stress. Sirtuins are NADdependent deacetylases and monoadenosine diphosphateribosyl transferases that regulate lipid and glucose metabolism, DNA repair, control cell survival, thermogenesis, insulin secretion, endothelial nitric oxide synthetase (eNOS), p53, and possibly mitochondrial flux [19]. Model organisms have suggested a role of Sirtiuns in aging [19]. Sirt 1 regulates autophagy under starvation conditions. In aging model animals, Sirt 1 is increased with stress in myocytes and may serve as antiaging agent [20]. Sirt 3 in excess prevents cardiac hypertrophy by reducing ROS-dependent signaling [21]. Many metabolic changes, such as accumulation of
TABLE 1: Pro- and antiaging factors.

\begin{tabular}{ll}
\hline Pro-aging & Antiaging \\
\hline Reactive O2 (ROS) & Klotho hormone \\
Hyperperoxides & Melatonin hormone \\
DNA damage & Sirtuins \\
Ultraviolet light & WNT \\
Telomere attrition & Dietary/Calorie \\
WNT pathway & Restriction \\
Increased target of rapamycin (TOR) & Antioxidants \\
activation & Resveratrol (Sirtuin \\
Reduced heat shock protein function & activator) \\
Defective lysosomes & Reduced TOR and \\
\hline
\end{tabular}

altered proteins, advanced glycation end-products (AGE), toxic methylglyoxal, occur with aging [22] and these changes contribute to abnormal mitochondrial function.

2.6. Immunologic Aging. The participating cells of the innate and adaptive immune responses are affected by aging (immunoscenecence) due to reduction of thymic cell population, affinity of B-cell-derived immunoglobulins, and impaired function of CD3 + T-cells [23]. Other participants in innate immune response such as natural killer cells (NK cells) show reduced numbers and cytotoxic activity, dendritic cells and monocytes show reduced phagocytic functions, FasL, IL-12, and tumor necrosis factor (TNF-)alpha, and increased IL-10 with age [24]. The serum levels of the inflammatory mediator and chemokine, interleukin-6 (IL-6) increases with age [25] while its receptor declines though not directly responsible for rising IL-6 and may be influenced by diet and exercise.

2.7. $p 53$ and Aging. The genome protector and complex transcriptional factor p53 has a role in aging. p53 is involved in many signaling pathways (DNA damage and repair signaling) and functions in cell death pathways(apoptosis and autophagy) and determines cell fate [26, 27]. p53 promotes aging via its induction of cell senescence that could compromise tissue renewal and pro-oxidant functions; it is antiageing by its stabilizing genome integrity and restraining glycolysis and many mouse models confirm the contribution of p53 in protecting genome integrity. p53 is a participant in stem cell fate and potential differentiation.

2.8. Sestrins and Aging. Sestrin family of proteins (sestrin 1, sestrin 2, and sestrin 3) were described in the past decade and are induced by oxidative stress, and hypoxia. Sestrins are present in all adult tissues. Sestrins interact with and inhibit $\mathrm{mTOR}$, interact and regulated by FoxO and p53, and reduce effects of oxidative stress by generating peroxiredoxins; these sestrins increase autophgy, reduce ROS and cell growth $[28,29]$. 


\section{Telomeres, Telomerase and Aging}

Telomeric DNA length is dependent on genetic inheritance, oxidative stress and telomerase activity [30]. The terminal (TTAGGG)n repeats vary from $5-15 \mathrm{~kb}$ in length and losses occur with each cell division. Telomere length is maintained by telomerase activity. Telomerase consists of telomerase reverse transcriptase (hTERT), dyskerin and telomerase RNA(hTR) and telomerase adds repeats of (TTAGGG)n to ends of telomeres. Epigenetic changes in telomeres due to methylation and retinoblastoma protein affect telomere length and recombination [31]. It is known that telomeres are transcribed by RNA polymeraseII to create noncoding RNAs (TERRA or TelRNA) and accumulation of these noncoding TelRNAs occurs with aging [31]. Telomerase activity is high in embryonic cells, multipotent germ cells and cancer cells. The continuing loss of telomeres over time reduces replicative capacity of dividing cells. Telomere length varies among individuals, within cells and this variation depends on subtelomeric sequences. The minimum length is $2 \mathrm{~kb}$ but can be as low as $300 \mathrm{bp}$. Model organisms such as mice have longer telomeres. Telomere length, measured by confocal telomere quantitative fluorescence (Q-FISH) is longest in stem cell niches [32]. Gender- and organrelated telomere length is described in model organisms [33]. Telomere length in young persons with paternal history of early myocardial infarction is generally shorter than controls [34].

Telomere loss can subject cells to replicative senescence, apoptosis by activating DNA damage signaling, p53-p21retinoblastoma axis signaling pathways and hence genome instability [35]. Telomere attrition as a trigger for cellular senescence may subsequently affect the heart by (a) in the wound healing response by reduced inflammatory response and (b) limiting adult stem cell life span [36]. Telomere induced senescence leads to the so-called "senescence secretome" pathway that is characterized by (i) reduced IGF1 and Wnt2, (ii) increased IL-6 and its receptor, (iii) increased interferon gamma and cell death and (iv) increased matrix metalloproteinases 1 and 3 , reduced fibronectin and collagen.

In both aging humans with telomere attrition and model mouse strains with TERC+/-, atherosclerosis and blood pressure increase with age, left ventricular function and wound healing response are impaired [37]. In population based study of telomere length and longevity of elderly persons, telomere length was associated with years of healthy life (YHL) but nor cardiovascular disease [38]. In human studies, telomere reduction may contribute to premature myocardial infarction [39].

The factors that are involved in human longevity have been sought through twin studies and multiple epidemiologic analysis. These studies, though imperfect and mainly done in a single country or a defined population groups, have found contribution of many of the factors to human longevity as summarized above for model organisms including heat shock proteins, IL-6, Sirtuins, Klotho [40].

\section{Aging Heart before Myocardial Infarction (Part of the Aging Cardiovascular System)}

Normal aging affects many components of the cardiovascular system. The heart undergoes increased left ventricular thickness, increased atrial size, reduced reserve, increased vascular diameter and wall stiffness and endothelial dysfunction $[41,42]$. In addition, standing heart rate decreases with age [43]. Precursor/stem cells (c-kit and sca-1 positive) in human myocardium age and promote heart failure [44]. Age-related gene expression changes in human are described but the findings are limited by sample numbers [45]. In mouse models of wild-type and IGF-1 transgenic mice, aging is accompanied by myocyte senescence, increased apoptosis, necrosis, myocyte hypertrophy, loss of telomererelated protein TRF2 but not TRF1 and reducing telomere length [46]. In rat hearts, aging leads to increase in cytosolic cytochrome $\mathrm{C}$, drop in apoptosis markers Bcl-2 and Bax, and increased lipid peroxidation [47]. Furthermore, aging hearts show defective autophagy in clearing accumulating damaged and oxidized lipids, damage and "large mitochondria" [48]. The aged heart, therefore is disadvantaged before any onset of myocardial ischemia and the extra burden of reperfusion.

\section{Effects of Aging on Myocardial Infarction and Remodeling}

Myocardial infarction involves several phases (i) myocyte damage and cell death (apoptosis, autophagy and necrosis), (ii) activation of and recruiting of inflammatory cells, (iii) mesenchymal/stem/progenitor cell response, recruitment and migration to infarct site and (iv) wound healing response and collagen deposition [49]. For the preconditioned and aging heart, the events of myocardial infarction are clearly additional burden and heavy stress. In addition ROS induces mitochondrial deficits and ATP depletion after myocardial infarction and reperfusion [50].

5.1. Effects on Cell Death. Myocardial infarction is associated with all cell death types-necrosis is best recognized but apoptosis and autophagy contribute to border zone and remote zone cell death [51]. In the aging heart, cell death is already elevated and renewal of lost cardiomyocytes is limited [44].

5.2. Effects on Inflammation. The inflammatory activation after MI involves both the innate and adaptive immune responses to damaged cells, DNA and membrane lipids. Recent studies in aging mouse models of MI demonstrated reduced migration of inflammatory cells and hence reduced cytokine expression and their downstream effects on wound repair [52].

5.3. Effects on Wound Repair. Mesenchymal stem cells are recruited to the infarct zone (IZ) as part of the wound repair response [53]. Although cardiac stem cells are recognized, they are few and have long turn-over interval [54]. The studies on diseased and aging human hearts showed attrtion of c-kit+ve cells compared to nondiseased hearts and contributed to heart failure [44]. This finding and the general 
TABle 2: Summary of factors in Post-MI remodeling and heart failure.

\begin{tabular}{|c|c|}
\hline $\begin{array}{l}\text { Parameter of } \\
\text { remodeling }\end{array}$ & Effects on the heart \\
\hline \multirow{5}{*}{$\begin{array}{l}\text { Changes in } \\
\text { Myocytes }\end{array}$} & Myocyte hypertrophy \\
\hline & Fetal gene expression \\
\hline & Increased myocyte length \\
\hline & Decreased myocyte numbers \\
\hline & Increased myocyte cell death \\
\hline \multirow{4}{*}{$\begin{array}{l}\text { Changes in cardiac } \\
\text { morphology }\end{array}$} & Left ventricular dilatation \\
\hline & Increased extracellular matrix \\
\hline & Increased spherical shape \\
\hline & Increased wall thinning \\
\hline \multirow{3}{*}{$\begin{array}{l}\text { Changes in left } \\
\text { ventricular } \\
\text { function }\end{array}$} & Increased oxygen consumption \\
\hline & Increased adrenergic response \\
\hline & $\begin{array}{l}\text { Increased end systolic and diastolic } \\
\text { dysfunction }\end{array}$ \\
\hline
\end{tabular}

knowledge of aging hematopeoitic and mesenchymal stem cells may add to the impairment of recruiting stem cells to infarct zone. Wnt signaling also participates in wound healing [5].

5.4. Effects on Cardiac Hypertrophy. Post-MI remodeling is defined by (a) Infarct expansion and acute dilatation of infarct zone; (b) dilatation of noninfarct zone and increased sphericity, leading to poor function; (c) ventricular (myocyte) hypertrophy, myocytolysis, myocyte loss, myocyte lengthening, altered extracellular matrix [55]. The model for postMI remodeling in humans has been characterized as the "Bio-mechanical model" [56] which involves structural, functional changes in the heart and the activation of neurohormal response $[57,58]$ and are the cornerstone for targeted therapeutics and clinical management. Myocardial hypertrophy is complex and promoted by stress signaling, calcium levels, growth factors, phosphoinositide-3-kinase (PI3K) and mitogen-activated protein kinase (MAPK) pathways, and fibroblasts. There are intrinsic negative regulators of cardiac hypertrophy which include Glucose synthase kinase (GSK), caveolin-3 and calcineurin inhibitors [59]. Aging mice after myocardial infarction show reduced collagen deposition, and myofibroblast induction with progression of remodeling and limited response to transforming growth factor (TGF-beta) [52]. In aged rats, postmyocardial infarction mortality and all left ventricular function parameters (reduced cardiac index, peak pressure and end-diastolic pressure and increased enddiastolic volume index) were impaired [60]. The emerging contributions of microRNAs (cardiac-specific) to angiogenesis, myocyte proliferation, myocyte apoptosis and fibrosis are not fully explored in relation to the aging heart and remodeling [61]. It is logical therefore that all components of the initiating MI and postMI remodeling are subject to aging effect and need full attention (Table 2).

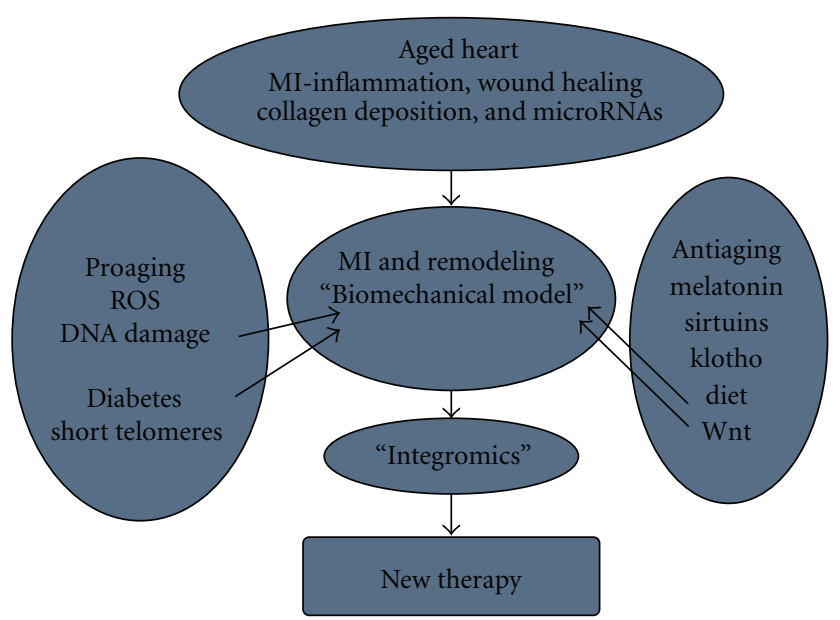

Figure 1: The possible interactions between Pro- and Antiaging factors is indicated. The proteins and their genes are well characterized but defined interactions in their signaling pathways and expression patterns during myocardial infarction and remodeling are not known. The knowledge of these interactions may help in further drug discovery.

\section{Future and Emerging Approaches to Post-MI Remodeling and Heart Failure Management}

In the search for "aging" factors, Human Aging Genomic Resources is now available and expanding [62]. The information generated should help promote more appropriate approaches to the so-called "aging therapies" [63]. The complex interactions of many signaling pathways in heart failure clearly calls for integrated approach to preclinical studies of aging effects on postinfarct remodeling. Although the conceptual framework for postinfarct remodeling is strong and relevant for clinical management, newer models that incorporate all available information may be needed [64]. A systems based approach using all "omics" tools may be the way for better understanding of aging in general and specifically for cardiovascular discovery (Figure 1) as suggested for heart failure $[65,66]$. The suggestion that signaling pathways modulate with age [67] also means that system wide assessment of the effects of pro- and antiaging factors on cardiomyocyte function will be the optimal approach to the discovery of age-modulating pathways.

\subsection{Do We Target Telomerase Function and Telomeres?}

Telomerase inhibition (using nucleoside analogs or Glucose synthesase kinase 3 inhibitors) are proposed for other conditions but obviously not needed to modify aging and stem cells [68].

\subsection{Do We Promote Wound Healing and Reduce Cardiac Hypertrophy?}

6.2.1. Emerging Use of Stem Cells for Infarct Repair. There are many attempts to use hematopoeitic, peripheral blood or mesensenchymal stem cells to mitigate the wound repair in 
infarct hearts [69]. The studies and clinical trials have used chemokines (Granulocyte-colony stimulating factor-GCSF) to promote engraftment combined with direct implantation into infarct zone via the coronary artery and have produced results in model animals and humans ([70, 71] but need careful assessments of cell types used and long-term regenerative potential [72]. In addition, the aged cardiac environment may influence the capacity of mobilized, transplanted, or implanted stem/progenitor cells to differentiate and function [73].

Induced pluripotent cells (iPSCs) generated by retroviral vectors carrying Oct4, Sox2, and Klf4, are now a potential source cells for cardiac repair [74, 75]. Biological and molecular profiles of iPSCs and potential drawbacks on their use have been reviewed recently [76]. Alternate method for generating same cells, RNA-induced pluripotent cells (RiPSCs) is described [77]. iPSCs have been used in mouse models of myocardial infarction and repair and the cells can repair infarcts by producing functional cardiomyocytes, smooth muscle cells and vessels [78]; a side effect is promoting teratomas.

A recent study in mice illustrates the need to verify the stem cell capacity to generate myocytes and repair infarcts and reestablish function [79]. The progenitor and stem cells used in studies and clinical trials probably have varying potentials and have differing stem cell biomarkers such as isl1, sca-1 like, Nkx2.5, GATA4, Lin, c-kit and others [80]. The cells with regenerative capacity used in infarct repair include (a) mesenchymal (b) hematopoeitic (circulating), embryonic stem cells and (d) residual cardiac stem cells in the myocardium. Many mouse models have reported functional improvement after infusion or activation of stem cells of varying potential or type (cardiac progenitors, mesenchymal stem cells, human hematopoeitic stem cells, or embryonic stem cells) [81-84]. Studies in humans including clinical trials are providing support for the mouse models [85]. Some studies show no improvement, as in the swine model of large infarcts using mononuclear cells [86] and older mouse models that had poorer engraftment of stem cells [87]. In reviewing five clinical trials [88], it was found that gains in ejection fraction were not universal and depended on length of study and time of assessment. Additional meta-analyses have highlighted the varied methods of delivery including intracoronary and endocardial, use of different stem cells [89] embryonic, adult) and the varied observation periods; the average increase left ventricular ejection fraction (LVEF) was $3 \%$ in ten randomized trials. The human studies have not separated young and older infarct patients to determine differences in engraftment and functional recovery. In order to properly compare results in model animals and in humans, complete or comparable data sets on the use of stem cells should be available.

6.2.2. Other Ways to Reverse Cardiac Hypertrophy. Melatonin, the pineal hormone and antioxidant [90], is a protector of cardiac reperfusion injury [91]. Melatonin, potentially are antiproliferative and antiapoptotic [92]. Ischemia and reperfusion related ROS-induced myocyte damage is reduced by melatonin in mouse models [93]. Sirt 3 overexpression in mouse models can inhibit cardiac hypertrophy [21] by activation of Foxo3a-dependent antioxidants and inhibition of reactive oxygen species (ROS) dependent signaling. Melatonin also reduced reperfusion induced fibrillation and arrythmias [94]. Some investigators suggest targeting the ROS-induced damages after reperfusion [50] and the use of statins, selective xanthine oxidase inhibitor oxipurinol [95].

6.2.3. Age Well to Improve the Heart. This is the simple part as long as ageing is not reformulated as an illness or disease. As aging is partly dependent on the environment, dietary approaches are simple. Dietary/calorie restriction is a well-defined way to promote longevity [96] and leads to activation of nutrient sensors (TOR-target of rapamycin) and Sirtuins which promote cell cycle progression, improve detoxification and mitochondrial biogenesis. Zinc in diet can limit aging in Klotho knockout mice [97]. Lipoic acid in model mice reduced oxidative stress [98]. Melatonin is also projected to improve aging-related immune senescence and change both the T-cell and cytokine profile [99]. An activator of Sirtuin and AMPK pathways, Resveratrol [100] has been promoted as antiaging supplement. Healthy habits such as diet including vitamins [101] and antioxidants such as blue-berries [102] are proposed to promote healthy aging. Tea-derived flavonoids (catechins and theafavins) via their proposed antioxidant, antiinflammatory could protect from age-related effects [103]. Exercise [104] and other preventions could assist in healthy aging.

\section{Summary}

The contributions of the multiple pro-and antiaging factors to human aging are of great interest and are now better understood. The contributions of environmental, genetic and biologic factors (telomere attrition, sestrins, Sirt 1, klotho, diabetes, p53) to the function of the aging heart and their possible effects on the outcome of myocardial infarction, postMI remodeling and heart failure are important areas of research. An integrated approach to future studies in model animals and humans with myocardial infarction may uncover new therapeutic targets. There are emerging therapeutic options such as "stem cell therapy" for myocardial infarction. All of these advances will certainly benefit all aging individuals in future.

\section{Acknowledgments}

The author appreciates and acknowledges the support and encouragement of his wife, Mrs. Augusta. E Idikio, RN. BN. Many thanks are due to Professor Y. Coe (Cardiology) for reading the paper. He is also grateful to Prof. B. I. Jugdutt for the opportunity to participate in this very exciting area of postMI remodeling. 


\section{References}

[1] T. B. L. Kirkwood, "Understanding the odd science of aging," Cell, vol. 120, no. 4, pp. 437-447, 2005.

[2] M. Kuningas, S. P. Mooijaart, D. Van Heemst, B. J. Zwaan, P. E. Slagboom, and R. G. J. Westendorp, "Genes encoding longevity: from model organisms to humans," Aging Cell, vol. 7, no. 2, pp. 270-280, 2008.

[3] H. Kurosu, M. Yamamoto, J. D. Clark et al., "Suppression of aging in mice by the hormone Klotho," Science, vol. 309, no. 5742, pp. 1829-1833, 2005.

[4] Y. Takahashi, M. Kuro-O, and F. Ishikawa, "Aging mechanisims," Proceedings of the National Academy of Sciences of the United States of America, vol. 97, no. 23, pp. 12407-12408, 2000.

[5] K. Maiese, F. Li, Z. Z. Chong, and Y. C. Shang, "The Wnt signaling pathway: aging gracefully as a protectionist?" Pharmacology and Therapeutics, vol. 118, no. 1, pp. 58-81, 2008.

[6] S. Stewart, K. MacIntyre, S. Capewell, and J. J. V. McMurray, "Heart failure and the aging population: an increasing burden in the 21 st century?" Heart, vol. 89, no. 1, pp. 49-53, 2003.

[7] D. F. Terry, M. A. Wilcox, M. A. McCormick, and T. T. Perls, "Cardiovascular disease delay in centenarian offspring," Journals of Gerontology. Series A, vol. 59, no. 4, pp. 385-389, 2004.

[8] D. F. Terry, V. G. Nolan, S. L. Andersen, T. T. Perls, and R. Cawthon, "Association of longer telomeres with better health in centenarians," Journals of Gerontology. Series A, vol. 63, no. 8, pp. 809-812, 2008.

[9] J. P. De Magalhães, J. A. S. Cabral, and D. Magalhães, “The influence of genes on the aging process of mice: a statistical assessment of the genetics of aging," Genetics, vol. 169, no. 1, pp. 265-274, 2005.

[10] J. M. Zahn, S. Poosala, A. B. Owen et al., "AGEMAP: a gene expression database for aging in mice," PLoS genetics, vol. 3, no. 11, article e201, 2007.

[11] F. J. Giordano, "Oxygen, oxidative stress, hypoxia, and heart failure," Journal of Clinical Investigation, vol. 115, no. 3, pp. 500-508, 2005.

[12] C. Murdoch, M. Zhang, A. Cave, and A. Shah, "NADPH oxidase-dependent redox signaling in cardiac hypertrophy, remodeling and failure," Cardiovascular Research, vol. 71, pp. 208-215, 2006.

[13] D. B. Lombard, K. F. Chua, R. Mostoslavsky, S. Franco, M. Gostissa, and F. W. Alt, "DNA repair, genome stability, and aging," Cell, vol. 120, no. 4, pp. 497-512, 2005.

[14] S. K. Calderwood, A. Murshid, and T. Prince, "The shock of aging: molecular chaperones and the heat shock response in longevity and aging - a mini-review," Gerontology, vol. 55, no. 5, pp. 550-558, 2009.

[15] M. Yamamoto, J. D. Clark, J. V. Pastor et al., "Regulation of oxidative stress by the anti-aging hormone klotho," Journal of Biological Chemistry, vol. 280, no. 45, pp. 38029-38034, 2005.

[16] H. Liu, M. M. Fergusson, R. M. Castilho et al., "Augmented Wnt signaling in a mammalian model of accelerated aging," Science, vol. 317, no. 5839, pp. 803-806, 2007.

[17] D. E. Arking, G. Atzmon, A. Arking, N. Barzilai, and H. C. Dietz, "Association between a functional variant of the KLOTHO gene and high-density lipoprotein cholesterol, blood pressure, stroke, and longevity," Circulation Research, vol. 96, no. 4, pp. 412-418, 2005.
[18] M. Rota, N. LeCapitaine, T. Hosoda et al., "Diabetes promotes cardiac stem cell aging and heart failure, which are prevented by deletion of the p66 gene," Circulation Research, vol. 99, no. 1, pp. 42-52, 2006.

[19] T. Finkel, C. X. Deng, and R. Mostoslavsky, "Recent progress in the biology and physiology of sirtuins," Nature, vol. 460, no. 7255, pp. 587-591, 2009.

[20] R. R. Alcendor, S. Gao, P. Zhai et al., "Sirt1 regulates aging and resistance to oxidative stress in the heart," Circulation Research, vol. 100, no. 10, pp. 1512-1521, 2007.

[21] N. R. Sundaresan, M. Gupta, G. Kim, S. B. Rajamohan, A. Isbatan, and M. P. Gupta, "Sirt3 blocks the cardiac hypertrophic response by augmenting Foxo3a-dependent antioxidant defense mechanisms in mice," Journal of Clinical Investigation, vol. 119, no. 9, pp. 2758-2771, 2009.

[22] A. R. Hipkiss, "Energy metabolism, altered proteins, sirtuins and ageing: converging mechanisms?" Biogerontology, vol. 9, no. 1, pp. 49-55, 2008.

[23] K. Dorshkind, E. Montecino-Rodriguez, and R. A. J. Signer, "The ageing immune system: is it ever too old to become young again?” Nature Reviews Immunology, vol. 9, no. 1, pp. 57-62, 2009.

[24] A. Panda, A. Arjona, E. Sapey et al., "Human innate immunosenescence: causes and consequences for immunity in old age," Trends in Immunology, vol. 30, no. 7, pp. 325-333, 2009.

[25] M. Maggio, J. M. Guralnik, D. L. Longo, and L. Ferrucci, "Interleukin-6 in aging and chronic disease: a magnificent pathway," Journals of Gerontology. Series A, vol. 61, no. 6, pp. 575-584, 2006.

[26] F. Rodier, J. Campisi, and D. Bhaumik, "Two faces of p53: aging and tumor suppression," Nucleic Acids Research, vol. 35, no. 22, pp. 7475-7484, 2007.

[27] K. H. Vousden and C. Prives, "Blinded by the light: the growing complexity of p53,” Cell, vol. 137, no. 3, pp. 413431, 2009.

[28] J. H. Lee, R. Bodmer, E. Bier, and M. Karin, "Sestrins at the crossroad between stress and aging," Aging, vol. 2, no. 6, pp. 369-374, 2010.

[29] A. V. Budanov, J. H. Lee, and M. Karin, “Stressin' Sestrins take an aging fight," EMBO Molecular Medicine, vol. 2, no. 10, pp. 388-400, 2010.

[30] H. Riethman, "Human telomere structure and biology," Annual Review of Genomics and Human Genetics, vol. 9, pp. 1-19, 2008.

[31] S. Schoeftner and M. A. Blasco, "A higher order of telomere regulation: telomere heterochromatin and telomeric RNAs," EMBO Journal, vol. 28, no. 16, pp. 2323-2336, 2009.

[32] I. Flores, A. Canela, E. Vera, A. Tejera, G. Cotsarelis, and M. A. Blasco, "The longest telomeres: a general signature of adult stem cell compartments," Genes and Development, vol. 22, no. 5, pp. 654-667, 2008.

[33] H. Cherif, J. L. Tarry, S. E. Ozanne, and C. N. Hales, "Ageing and telomeres: a study into organ- and genderspecific telomere shortening," Nucleic Acids Research, vol. 31, no. 5, pp. 1576-1583, 2003.

[34] K. D. Salpea, V. Nicaud, L. Tiret, P. J. Talmud, and S. E. Humphries, "The association of telomere length with paternal history of premature myocardial infarction in the European Atherosclerosis Research Study II," Journal of Molecular Medicine, vol. 86, no. 7, pp. 815-824, 2008. 
[35] R. Capper, B. Britt-Compton, M. Tankimanova et al., "The nature of telomere fusion and a definition of the critical telomere length in human cells," Genes and Development, vol. 21, no. 19, pp. 2495-2508, 2007.

[36] P. D. Adams, "Healing and hurting: molecular mechanisms, functions, and pathologies of cellular senescence," Molecular Cell, vol. 36, no. 1, pp. 2-14, 2009.

[37] L. S. M. Wong, H. Oeseburg, R. A. De Boer, W. H. Van Gilst, D. J. Van Veldhuisen, and P. Van Der Harst, "Telomere biology in cardiovascular disease: the TERC mouse as a model for heart failure and ageing," Cardiovascular Research, vol. 81, no. 2, pp. 244-252, 2009.

[38] O. T. Njajou, W. C. Hsueh, E. H. Blackburn et al., "Association between telomere length, specific causes of death, and years of healthy life in health, aging, and body composition, a population-based cohort study," Journals of Gerontology. Series A, vol. 64, no. 8, pp. 860-864, 2009.

[39] M. D. Edo and V. Andrés, "Aging, telomeres, and atherosclerosis," Cardiovascular Research, vol. 66, no. 2, pp. 213-221, 2005.

[40] K. Christensen, T. E. Johnson, and J. W. Vaupel, “The quest for genetic determinants of human longevity: challenges and insights," Nature Reviews Genetics, vol. 7, no. 6, pp. 436-448, 2006.

[41] E. G. Lakatta, "Arterial and cardiac aging: major shareholders in cardiovascular disease enterprises-part III: cellular and molecular clues to heart and arterial aging," Circulation, vol. 107, no. 3, pp. 490-497, 2003.

[42] E. G. Lakatta, "Arterial and cardiac aging: major shareholders in cardiovascular disease enterprises-part III: cellular and molecular clues to heart and arterial aging," Circulation, vol. 107, no. 3, pp. 346-354, 2003.

[43] J. B. Schwartz, W. J. Gibb, and T. Tran, "Aging effects on heart rate variation," Journals of Gerontology, vol. 46, no. 3, pp. M99-M106, 1991.

[44] P. Anversa, J. Kajstura, A. Leri, and R. Bolli, "Life and death of cardiac stem cells: a paradigm shift in cardiac biology," Circulation, vol. 113, no. 11, pp. 1451-1463, 2006.

[45] L. W. Stanton, L. J. Garrard, D. Damm et al., "Altered patterns of gene expression in response to myocardial infarction," Circulation Research, vol. 86, no. 9, pp. 939-945, 2000.

[46] D. Torella, M. Rota, D. Nurzynska et al., "Cardiac stem cell and myocyte aging, heart failure, and insulin-like growth factor-1 overexpression," Circulation Research, vol. 94, no. 4, pp. 514-524, 2004.

[47] S. Phaneuf and C. Leeuwenburgh, "Cytochrome c release from mitochondria in the aging heart: a possible mechanism for apoptosis with age," American Journal of Physiology, vol. 282, no. 2, pp. R423-R430, 2002.

[48] A. Terman and U. T. Brunk, "Autophagy in cardiac myocyte homeostasis, aging, and pathology," Cardiovascular Research, vol. 68, no. 3, pp. 355-365, 2005.

[49] S. Frantz, J. Bauersachs, and G. Ertl, "Post-infarct remodelling: contribution of wound healing and inflammation," Cardiovascular Research, vol. 81, no. 3, pp. 474-481, 2009.

[50] G. Solaini and D. A. Harris, "Biochemical dysfunction in heart mitochondria exposed to ischaemia and reperfusion," Biochemical Journal, vol. 390, no. 2, pp. 377-394, 2005.

[51] Y. Matsui, H. Takagi, X. Qu et al., "Distinct roles of autophagy in the heart during ischemia and reperfusion: roles of AMP-activated protein kinase and beclin 1 in mediating autophagy," Circulation Research, vol. 100, no. 6, pp. 914-922, 2007.
[52] M. Bujak, H. J. Kweon, K. Chatila, NA. Li, G. Taffet, and N. G. Frangogiannis, "Aging-related defects are associated with adverse cardiac remodeling in a mouse model of reperfused myocardial infarction," Journal of the American College of Cardiology, vol. 51, no. 14, pp. 1384-1392, 2008.

[53] M. F. Pittenger and B. J. Martin, "Mesenchymal stem cells and their potential as cardiac therapeutics," Circulation Research, vol. 95, no. 1, pp. 9-20, 2004.

[54] O. Bergmann, R. D. Bhardwaj, S. Bernard et al., "Evidence for cardiomyocyte renewal in humans," Science, vol. 324, no. 5923, pp. 98-102, 2009.

[55] M. A. Pfeffer and E. Braunwald, "Ventricular remodeling after myocardial infarction: experimental observations and clinical implications," Circulation, vol. 81, no. 4, pp. 11611172,1990

[56] D. L. Mann and M. R. Bristow, "Mechanisms and models in heart failure: the biomechanical model and beyond," Circulation, vol. 111, no. 21, pp. 2837-2849, 2005.

[57] R. G. McKay, M. A. Pfeffer, and R. C. Pasternak, "Left ventricular remodeling after myocardial infarction: a corollary to infarct expansion," Circulation, vol. 74, no. 4, pp. 693-702, 1986.

[58] B. I. Jugdutt, "Ventricular remodeling after infarction and the extracellular collagen matrix: when is enough enough?" Circulation, vol. 108, no. 11, pp. 1395-1403, 2003.

[59] S. E. Hardt and J. Sadoshima, "Negative regulators of cardiac hypertrophy," Cardiovascular Research, vol. 63, no. 3, pp. 500-509, 2004.

[60] T. E. Raya, M. Gaballa, P. Anderson, and S. Goldman, "Left ventricular function and remodeling after myocardial infarction in aging rats," American Journal of Physiology, vol. 273, no. 6, pp. H2652-H2658, 1997.

[61] M. V. Latronico and G. Condorelli, "MicroRNAs and cardiac pathology," Nature reviews. Cardiology, vol. 6, no. 6, pp. 419429, 2009.

[62] J. P. de Magalhães, A. Budovsky, G. Lehmann et al., "The human ageing genomic resources: online databases and tools for biogerontologists," Aging Cell, vol. 8, no. 1, pp. 65-72, 2009.

[63] S. I. Rattan, "Anti-ageing strategies: prevention or therapy? Showing ageing from within," EMBO Reports, vol. 6, pp. S25S29, 2005.

[64] Z. R. Yousef, S. R. Redwood, and M. S. Marber, "Postinfarction left ventricular remodelling: where are the theories and trials leading us?" Heart, vol. 83, no. 1, pp. 76-80, 2000.

[65] C. G. Dos Remedios, C. C. Liew, P. D. Allen, R. L. Winslow, J. E. Van Eyk, and M. J. Dunn, "Genomics, proteomics and bioinformatics of human heart failure," Journal of Muscle Research and Cell Motility, vol. 24, no. 4-6, pp. 251-260, 2003.

[66] J. O. Mudd and D. A. Kass, "Tackling heart failure in the twenty-first century," Nature, vol. 451, no. 7181, pp. 919-928, 2008.

[67] M. E. Carlson, H. S. Silva, and I. M. Conboy, "Aging of signal transduction pathways, and pathology," Experimental Cell Research, vol. 314, no. 9, pp. 1951-1961, 2008.

[68] J. L. Mergny, J. F. Riou, P. Mailliet, M. P. Teulade-Fichou, and E. Gilson, "Natural and pharmacological regulation of telomerase," Nucleic Acids Research, vol. 30, no. 4, pp. 839865, 2002.

[69] C. Partovian and M. Simons, "Stem cell therapies in cardiovascular disease. A "realistic" appraisal," Drug Discovery Today, vol. 5, no. 1, pp. 73-78, 2008. 
[70] M. Yousef, C. M. Schannwell, M. Köstering, T. Zeus, M. Brehm, and B. E. Strauer, "Clinical benefit and long-term outcome after intracoronary autologous bone marrow cell transplantation in patients with acute myocardial infarction," Journal of the American College of Cardiology, vol. 53, no. 24, pp. 2262-2269, 2009.

[71] H. Drexler and K. Wollert, "Bone marrow cell thrapy for MIgoal achieved," Nature Reviews Cardiology, vol. 6, pp. 615616, 2009.

[72] T. Reffelmann, S. Könemann, and R. A. Kloner, "Promise of blood- and bone marrow-derived stem cell transplantation for functional cardiac repair. Putting it in perspective with existing therapy," Journal of the American College of Cardiology, vol. 53, no. 4, pp. 305-308, 2009.

[73] J. M. Edelberg and V. L. T. Ballard, "Stem cell review series: regulating highly potent stem cells in aging: environmental influences on plasticity," Aging Cell, vol. 7, no. 4, pp. 599-604, 2008.

[74] A. Chiriac, T. J. Nelson, R. S. Faustino, A. Behfar, and A. Terzic, "Cardiogenic induction of pluripotent stem cells streamlined through a conserved SDF-1/VEGF/BMP2 integrated network," PLoS ONE, vol. 5, no. 4, article e9943, 2010.

[75] J. Zhang, G. F. Wilson, A. G. Soerens et al., "Functional cardiomyocytes derived from human induced pluripotent stem cells," Circulation Research, vol. 104, no. 4, pp. e30-e41, 2009.

[76] J. H. Hanna, K. Saha, and R. Jaenisch, "Pluripotency and cellular reprogramming: facts, hypotheses, unresolved issues," Cell, vol. 143, no. 4, pp. 508-525, 2010.

[77] L. Warren, P. D. Manos, T. Ahfeldt et al., "Highly efficient reprogramming to pluripotency and directed differentiation of human cells with synthetic modified mRNA," Cell Stem Cell, vol. 7, no. 5, pp. 618-630, 2010.

[78] T. J. Nelson, A. Martinez-Fernandez, S. Yamada, C. PerezTerzic, Y. Ikeda, and A. Terzic, "Repair of acute myocardial infarction with induced pluripotent stem cells induced by human stemness factors," Circulation, vol. 120, no. 5, pp. 408-416, 2009.

[79] I. J. Domian, M. Chiravuri, V. D. P. Meer et al., "Generation of functional ventricular heart muscle from mouse ventricular progenitor cells," Science, vol. 326, no. 5951, pp. 426-429, 2009.

[80] M. S. Parmacek and J. A. Epstein, "Pursuing cardiac progenitors: regeneration redux," Cell, vol. 120, no. 3, pp. 295-298, 2005.

[81] K. Matsuura, A. Honda, T. Nagai et al., "Transplantation of cardiac progenitor cells ameliorates cardiac dysfunction after myocardial infarction in mice," Journal of Clinical Investigation, vol. 119, no. 8, pp. 2204-2217, 2009.

[82] P. C. H. Hsieh, V. F. M. Segers, M. E. Davis et al., "Evidence from a genetic fate-mapping study that stem cells refresh adult mammalian cardiomyocytes after injury," Nature Medicine, vol. 13, no. 8, pp. 970-974, 2007.

[83] B. Léobon, I. Garcin, P. Menasché, J. T. Vilquin, E. Audinat, and S. Charpak, "Myoblasts transplanted into rat infarcted myocardium are functionally isolated from their host," Proceedings of the National Academy of Sciences of the United States of America, vol. 100, no. 13, pp. 7808-7811, 2003.

[84] C. Sesti, S. L. Hale, C. Lutzko, and R. A. Kloner, "Granulocyte colony-stimulating factor and stem cell factor improve contractile reserve of the infarcted left ventricle independent of restoring muscle mass," Journal of the American College of Cardiology, vol. 46, no. 9, pp. 1662-1669, 2005.
[85] R. S. Ripa, M. Haack-Sørensen, Y. Wang et al., "Bone marrow-derived mesenchymal cell mobilization by granulocyte-colony stimulating factor after acute myocardial infarction: results from the Stem Cells in Myocardial Infarction (STEMMI) trial," Circulation, vol. 116, no. 11, pp. I24-I30, 2007.

[86] R. De Silva, A. N. Raval, M. Hadi et al., "Intracoronary infusion of autologous mononuclear cells from bone marrow or granulocyte colony-stimulating factor-mobilized apheresis product may not improve remodelling, contractile function, perfusion, or infarct size in a swine model of large myocardial infarction," European Heart Journal, vol. 29, no. 14, pp. 17721782, 2008.

[87] S. Lehrke, R. Mazhari, D. J. Durand et al., "Aging impairs the beneficial effect of granulocyte colony-stimulating factor and stem cell factor on post-myocardial infarction remodeling," Circulation Research, vol. 99, no. 5, pp. 553-560, 2006.

[88] A. Rosenzweig, "Cardiac cell therapy-mixed results from mixed cells," New England Journal of Medicine, vol. 355, no. 12, pp. 1274-1277, 2006.

[89] B. J. Gersh, R. D. Simari, A. Behfar, C. M. Terzic, and A. Terzic, "Cardiac cell repair therapy: a clinical perspective," Mayo Clinic Proceedings, vol. 84, no. 10, pp. 876-892, 2009.

[90] R. Jockers, P. Maurice, J. A. Boutin, and P. Delagrange, "Melatonin receptors, heterodimerization, signal transduction and binding sites: what's new?" British Journal of Pharmacology, vol. 154, no. 6, pp. 1182-1195, 2008.

[91] C. H. Chen, G. R. Budas, E. N. Churchill, M. H. Disatnik, T. D. Hurley, and D. Mochly-Rosen, "Activation of aldehyde dehydrogenase-2 reduces ischemic damage to the heart," Science, vol. 321, no. 5895, pp. 1493-1495, 2008.

[92] F. Luchetti, B. Canonico, M. Betti et al., "Melatonin signaling and cell protection function," FASEB Journal, vol. 24, no. 10, pp. 3603-3624, 2010.

[93] G. Petrosillo, N. Di Venosa, M. Pistolese et al., "Protective effect of melatonin against mitochondrial dysfunction associated with cardiac ischemia-reperfusion: role of cardiolipin," FASEB Journal, vol. 20, no. 2, pp. 269-276, 2006.

[94] R. J. Reiter and D. X. Tan, "Melatonin: a novel protective agent against oxidative injury of the ischemic/reperfused heart," Cardiovascular Research, vol. 58, no. 1, pp. 10-19, 2003.

[95] U. Landmesser, K. C. Wollert, and H. Drexler, "Potential novel pharmacological therapies for myocardial remodelling," Cardiovascular Research, vol. 81, no. 3, pp. 519-527, 2009.

[96] A. Vaquero and D. Reinberg, "Calorie restriction and the exercise of chromatin," Genes and Development, vol. 23, no. 16, pp. 1849-1869, 2009.

[97] K. Morishita, A. Shirai, M. Kubota et al., "The progression of aging in klotho mutant mice can be modified by dietary phosphorus and zinc," Journal of Nutrition, vol. 131, no. 12, pp. 3182-3188, 2001.

[98] J. H. Suh, E. T. Shigeno, J. D. Morrow et al., “Oxidative stress in the aging rat heart is reversed by dietary supplementation with (R)- $\alpha$-lipoic acid," FASEB Journal, vol. 15, no. 3, pp. 700-706, 2001.

[99] V. Srinivasan, G. J. M. Maestroni, D. P. Cardinali, A. I. Esquifino, S. R. Pandi Perumal, and S. C. Miller, "Melatonin, immune function and aging," Immunity and Ageing, vol. 2, article 17, 2005. 
[100] M. A. Markus and B. J. Morris, "Resveratrol in prevention and treatment of common clinical conditions of aging," Clinical Interventions in Aging, vol. 3, no. 2, pp. 331-339, 2008.

[101] D. R. Thomas, "Vitamins in aging, health, and longevity," Clinical Interventions in Aging, vol. 1, no. 1, pp. 81-91, 2006.

[102] I. Ahmet, E. Spangler, B. Shukitt-Hale et al., "Blueberryenriched diet protects rat heart from ischemic damage," PLoS ONE, vol. 4, no. 6, article e5954, 2009.

[103] V. Stangl, H. Dreger, K. Stangl, and M. Lorenz, "Molecular targets of tea polyphenols in the cardiovascular system," Cardiovascular Research, vol. 73, no. 2, pp. 348-358, 2007.

[104] C. Le Page, P. Noirez, J. Courty, B. Riou, B. Swynghedauw, and S. Besse, "Exercise training improves functional postischemic recovery in senescent heart," Experimental Gerontology, vol. 44, no. 3, pp. 177-182, 2009. 


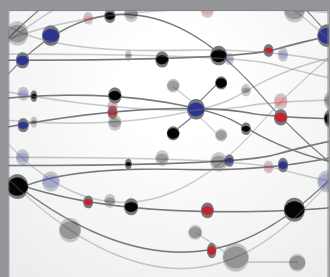

The Scientific World Journal
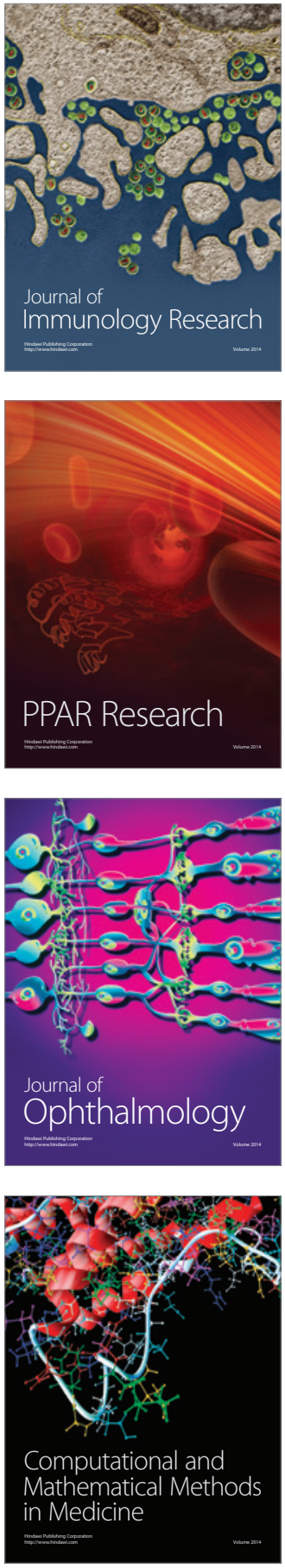

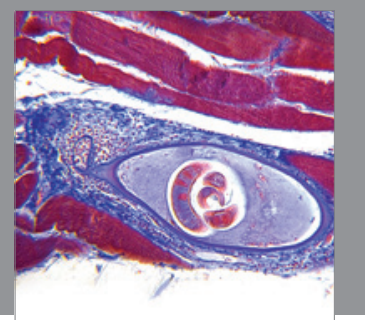

Gastroenterology

Research and Practice
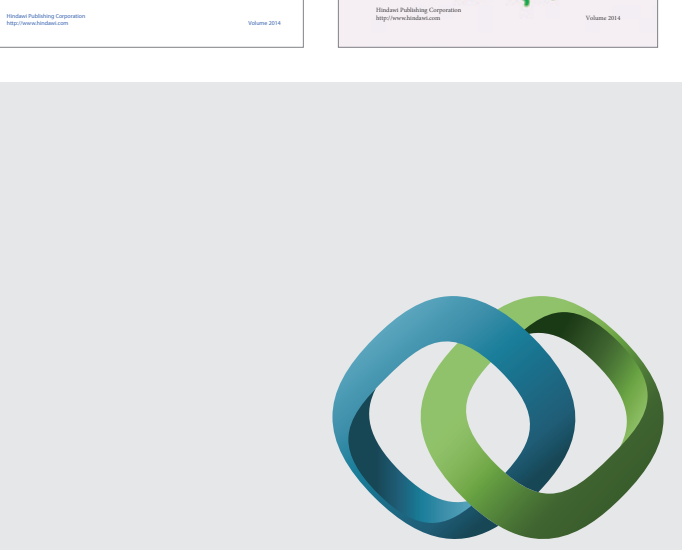

\section{Hindawi}

Submit your manuscripts at

http://www.hindawi.com
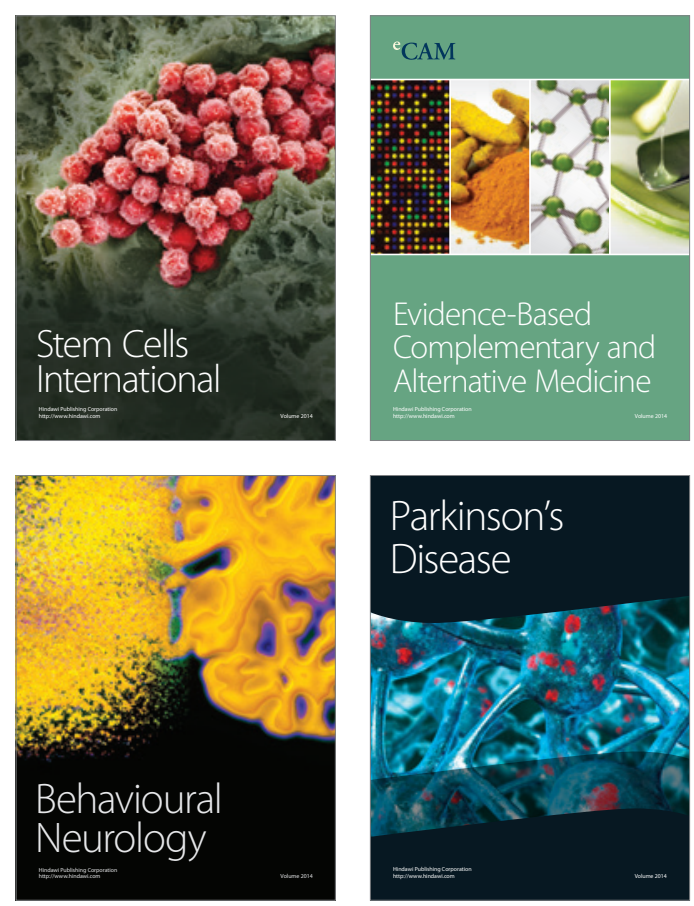

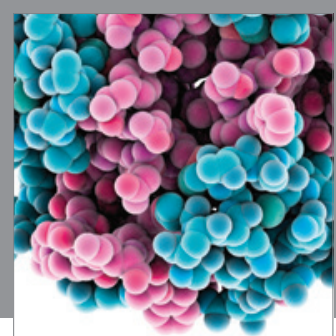

Journal of
Diabetes Research

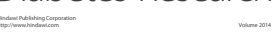

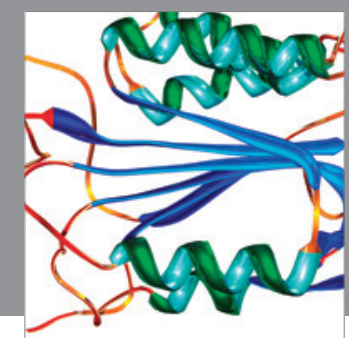

Disease Markers
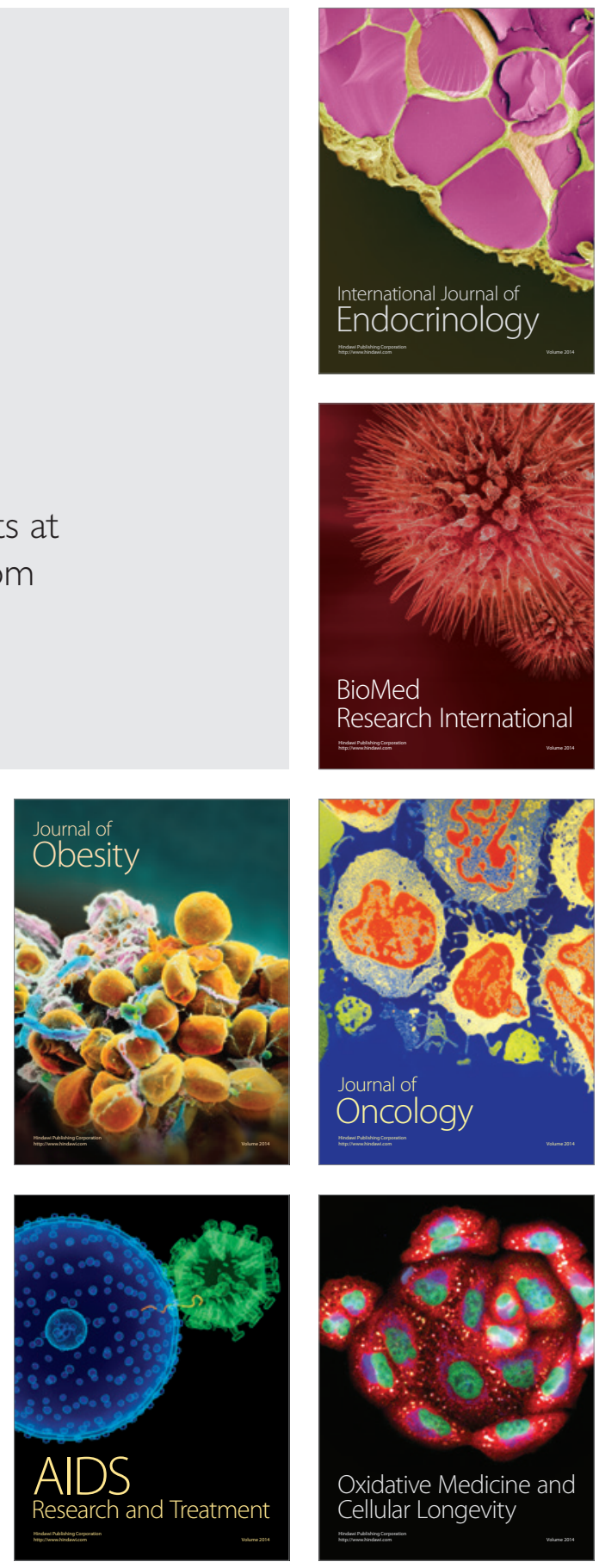